\title{
Gerenciamento por Sistemas ou Gerenciamento Participativo da Qualidade da Educação Brasileira
}

\author{
Vicente Falconi Campos*
}

A Gerência da Qualidade Total é hoje rcconhecida como um estágio evoluído do desenvolvimento da tecnologia de gerenciamento. $\mathrm{Na}$ abordagem da Qualidade Total a qualidade de um "produto" ("a educaçāo, dentro da abordagem sistemática, pode ser considerada como um produto") é conseguida pelo gerenciamento do sistema que "produz" este produto para um ou mais "clicntes". A missão de um sistema é obter a satisfação de seus clientes.

Um sistema, nesta abordagem, é gerenciado tendo como premissas:

(a) a especificação do "produto" deve ser feita para a total satisfaçāo dos clientes do sistema num processo denominado "desdobramento da qualidade";

(b) a produção deve ser conduzida de tal forma a garantir que o produto saia perfeitamente de acordo com as especificaçöes (na verdade deve superá-las) num processo denominado "desdobramento da funçäo qualidade";

(c) os resultados do sistema devem ser medidos numericamente de tal forma que, a partir destas indicações, seja possfvel atuar no sistema buscando as causas fundamentais dos resultados indesejáveis (problemas) num processo chamado "açäo corretiva".

Conceito de sistema - "Sistema é a composição de uma série de itens ("hardware", "software" e elemento humano) que são selecionados e alinhados para operar relacionando-se mutuamente para cumprir uma dada missão". Por exemplo: existe um sistema nacional de educação, sistemas estaduais de educação, sistemas municipais de educaçäo; mas existe também o sistema de lecionar cálculo numa Universidade qualquer, um sistema de fazer alimentos num grupo escolar, um sistema de limpar as salas de aula de uma escola de $2^{2}$ grau etc. $O$ ponto importante a ser salientado é que cada sistema tem seus próprios clientes, seus produtos e pessoas responsáveis por ele e que devem gerenciá-lo praticando

- Da Universidade Federal de Minas Gerais (196 UFMG 
as três funçöes mencionadas acima: desdobramento da qualidade, desdobramento da funçäo qualidade e açöes corretivas.

Sc a abordagem da qualidade da educação for assim pensada, fica evidenciado que cada sistema deveria ter a sua própria qualidade em função de seu produto e do seu cliente. Assim, é válido perguntar:

- "qual a qualidade do currículo para os cursos de engenharia civil?"

- "qual a qualidade do engenheiro civil formado pela UFMG?"

- "qual a qualidade do cnsino de cálculo da engenharia civil da UFMG?"

- "qual a qualidade da sala de aula (limpeza, iluminaçäo, ventilaçảo, projeçäo etc.) onde é lecionado cálculo para o curso de engenharia civil da UFMG?"

Cada pergunta, e evidentemente existiriam várias outras, se refere a um sistema diferente, com clientes diferentes, com produtos diferentes, com responsáveis diferentes. No entanto, falar em qualidade da educação c falar de tudo isto.

Portanto, ao se discutir a qualidade da educação brasileira é necessário antes de tudo:

(a) déinir o sistema que está sendo discutido;

(b) definir os clientes deste sistema (sociedade, empresas, indivíduo, pais, professor, scrvente, vigia etc.);

(c) definir os produtos deste sistema;

(d) condurir o desdobramento da qualidade c o desdobramento da funçäo qualidade;

(e) gerenciar o sistcma,

e.1) definindo as características de controle,

e.2) acompanhando as caractcrísticas de controle e

e.3) praticando a ação corretiva.

Gerenciamento de sistemas - $\mathrm{O}$ modelo de gerenciamento de sistemas através dos scus resultados ê o PDCA (Plan, Do, Check, Action), onde:

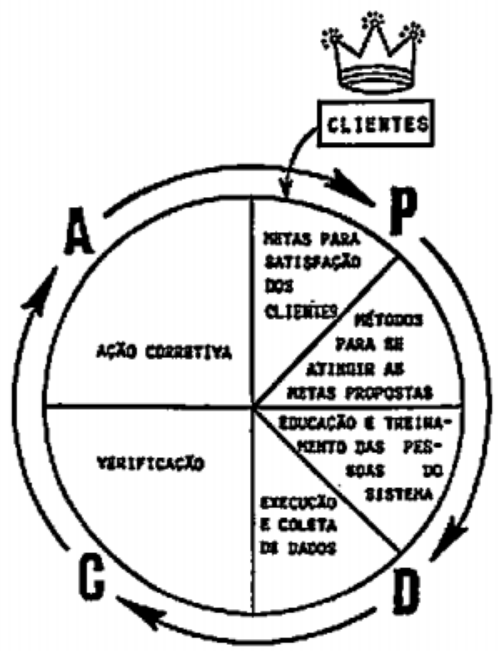

Figura I - Nélodo gerencial para o aperfeiçuamento contínuo de sistemas em função dos seus clientes 
Plan - Plancjamento do produto que inclui o desdobramento da qualidade e o desdobramento da função qualidade.

Do - Execução das açöes do sistema e colcta de dados para gerenciamento.

Check - Verificação das caracteristicas de controle do produto do sistema. Características de controle săo números que medem a qualidade total do produto de cada sistema e constam de:

qualidade - características exigidas pelo cliente do sistema;

custo - custo do produto do sistema;

prazo - prazo de entrega do produto;

quantidade - quantidade de produto produzido;

moral - nível médio de satisfação com o trabalho das pessoas que trabalham no sistema;

segurança - itens que afctam a segurança dos usuários do produto.

Action - (a) Quando os resultados acompanhados na etapa de vcrificação (Check) desviarem do padrão, deve-se eliminar os sintomas c também buscar as causas do resultado indesejável, eliminando-as.

(b) Quando os resultados acompanhados na ctapa "Check" estivercm dentro dos padröcs, mas estes padröcs forcm inaccitávcis, é então decidido melhorar o sistema rodando o PDCA, como mostra a Figura 2.

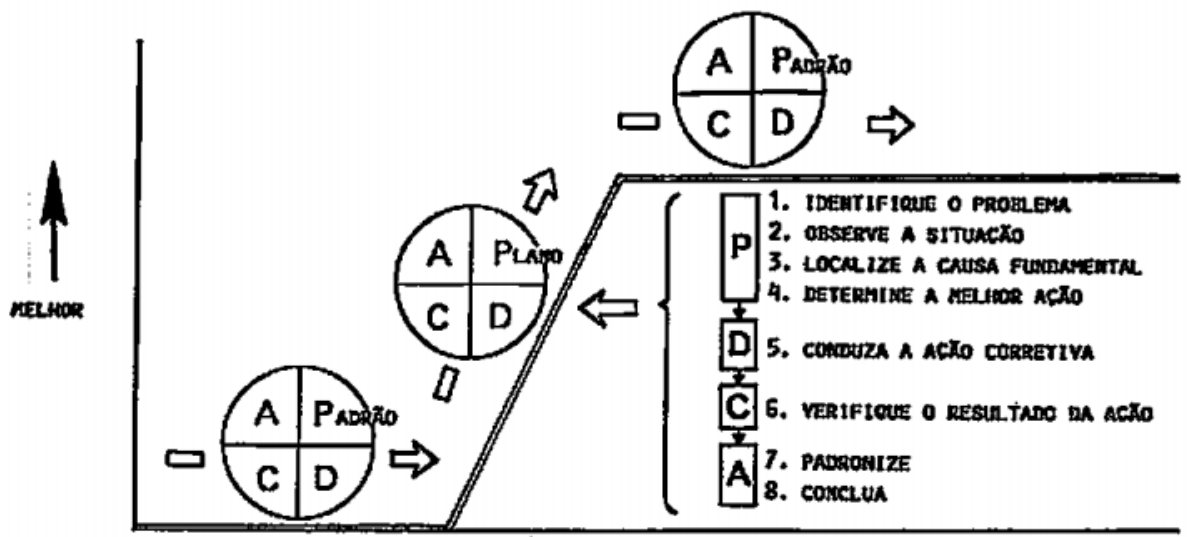




\section{Conclusōes}

- Propõe-se que a abordagem da qualidade da educação seja gerencial.

- As pessoas, de cima para baixo na hierarquia dos sistemas, devem ser educadas (mente) e treinadas (habilidade) a gerenciar a qualidade total.

- A qualidade, nos níveis desejados, só pode ser obtida num processo descentralizado e democrático, com envolvimento de todas as provas, cada uma se responsabilizando pelos resultados de seu sistema, ou seja, cada uma gerenciando seu próprio sistema para satisfação total do seu cliente. 